\title{
Effect of various plant starches on the quality characteristics of starch-based sweetened cow milk yoghurt
}

\author{
M. A. Alim*, A. Wadehra and A. K. Singh \\ National Dairy Research Institute, Karnal, Haryana, India and Department of Food Technology and Rural Industries, \\ Bangladesh Agricultural University, Mymensingh-2202, Bangladesh, *E-mail: maalim07@yahoo.com
}

\begin{abstract}
In this study, the textural, rheological and colour properties of different starch-based sweetened cow milk yoghurt were analyzed. Stickiness increased with increased addition level of modified starch for both homogenized (-2.231 to $-5.304 \mathrm{~N})$ and unhomogenized $(-1.505$ to $-4.834 \mathrm{~N})$ yoghurt sample. Firmness increased linearly for unhomogenized cow milk yoghurt sample at different incorporation level (3.019 to $4.887 \mathrm{~N}$ ) but the homogenized cow milk yoghurt samples did not shown any clear significant difference. Viscosity also increased with increased addition level of modified starch and unhomogenized yoghurt sample at different incorporation level of modified starch showed clear and significant difference from sample to sample. Firmness, stickiness and viscosity of potato starch-based cow milk yoghurt with homogenization did not show any significant difference, but unhomogenized yoghurt sample showed linear increase of viscosity and firmness that ranged from 0.213 to $0.525 \mathrm{~Pa}$.S and from 2.669 to $4.014 \mathrm{~N}$, respectively. Stickiness of unhomogenized sample also increased with increased potato starch incorporation level. Viscosity increased with increased corn starch incorporation for homogenized sample. The $\mathrm{pH}$ values were more or less similar and the colour values showed it was lightness as white for all cases. The highest incorporation level (2\%) was found for corn starch followed by potato (1.5\%) and modified (1.0\%) starch.
\end{abstract}

Keywords: Plant starches, Quality characteristics, Cow milk, Sweetened yoghurt

\section{Introduction}

Milk being a product of biological origin is extremely vulnerable to attack by microbes because it is a good source of nutrients such as carbohydrate $(4.5-5.25 \%)$, protein $(3-4 \%)$, fat $(3-4.5 \%)$, minerals (approx. $275 \mathrm{mg} / 100 \mathrm{~g}$ ) and vitamins (approx. $15 \mathrm{mg} / 100 \mathrm{~g}$ ) but the major component of milk is water $(87 \%)$ (Jones, 2002). The conversion of milk to yoghurt is agglomeration of casein micelles into a threedimensional network structure. Yoghurt is a popular fermented milk product that is produced round the world by acid coagulation of milk without drainage. Yoghurt are prepared by fermentation of milk bacterial cultures consisting of a mixture of Streptococuss subsp. thermophiles and Lactobacillus delbrueckii subsp. bulgaricus. Some bacterial strains used in cultures for manufactures of yoghurt or other fermented milks are known to produce polysaccharides outside the cell wall, called exopolysaccharides. The use of such strains modifies the physical properties of the fermented milk (Bouzar et al., 1997; Hassan et al., 2001). Yoghurt manufacturing processes are a little different depending on the country. But, it always comprises a lactic acid fermentation that brings milk to gelification due to destabilization of the protein system. Texture, consistency and flavour are its main quality parameters. Consistency of yoghurt is dependent on its structure, a protein network formed by casein micelles strings and/or clusters entrapping serum and fat globules (Kalab et al., 1983). Complex interactions can be established between these three components (Lucey and Singh, 1998). For yoghurt quality, texture is one of the essential components. Texture represents all the rheological and structural attributes perciptible by means of mechanical, tactile and, when appropriate, visual and auditory receptors for food products.

Lactic acid had been found as a key taste component in yoghurt from the taste point of view. Other organic acids and some additives are also involved in the taste of yoghurt (Tamime and Robinson, 1999). Carbonyl compounds such as acetaldehyde, diacetyl, acetoin and acetone are by far the most important components responsible for characteristic/typical aroma of plain yoghurt. These volatiles are produced during the fermentation stage (Kwak et al., 1996; Stanley, 1998; Tamime and Robinson, 1999). 
Starch is a carbohydrate consisting of a large number of glucose units joined together by glycosidic bonds. This polysaccharide is produced by most green plants as an energy store. It is the most common carbohydrate in human diets and is contained in large amounts in such staple food as potatoes, corn, wheat, rice, cassava, tapioca, etc. Pure starch is white in colour, tasteless and odourless powder that is insoluble in cold water or alcohol. Depending on the plant, starch generally contains 20 to $25 \%$ amylose and 75 to $80 \%$ amylopectin by weight (Brown and Poon, 2005). Starch is semi crystalline in nature with varying levels of crystallinity. The crystallinity is associated exclusively with the amylopectin component, while the amorphous regions mainly represent amylose (Zobel et al., 1998). The physico-chemical properties and functional characteristics of starch that are imparted to the aqueous systems and their uniqueness in various food applications vary with the biological origin (Svegmark and Hermansson, 1993). Starch contributes the textural properties to many foods. It has many industrial applications as a thickener, stabilizer, gelling agent, water retention agent, bulking agent, adhesive, etc. Many methods of characterizing starch have been developed. A large number of techniques such as differential scanning calorimetry (DSC), X-ray diffraction (Zobel et al., 1998) and small angle neutron scattering (Jenkins, 1994) have been used to study the gelatinization behaviour of starches.

Starch exhibits unique viscosity behaviour with change of temperature, concentration and shear rate (Nurul et al., 1999). The brabender visco-amylograph, rapid visco-analyser and rotational viscometers have been used for measuring starch paste viscosity. Many scientists have also used the dynamic rheometer for studying the viscoelastic or rheological properties of starches (Hsu, et al., 2000; Lii, et al., 1996).

Many times the addition of functional ingredients to food products results in the changes in the sensory properties of the product that could lead to a decrease in consumer's overall acceptability. Generally, consumers are not willing to accept functional foods which taste worse than conventional foods (Hilliam, 2003). For that reason, it is important to develop the functional food without changing the sensory characteristics because of consumers' reaction.

The purposes of this study were to prepare starch-based sweetened yoghurt (with homogenization and without homogenization) of cow milk and to evaluate the textural, rheological, colour and sensory properties of yoghurt.

\section{Materials and Methods}

The experiment was conducted in the Laboratory of Food Technology, Division of Dairy Technology, National Dairy Research Institute (NDRI), Karnal, Haryana, India.

\section{Chemicals}

Cow milk wascollected from NDRI, Karnal, Haryana, India; analytical grade sulfuric acid and amyl alcohol were purchased from Merck Specialities Pvt. Ltd., Mumbai, India. Potato and corn starch were procured from Aryan International, Jonapur, New Delhi, India. The DELVO DSL Direct set ${ }^{\mathrm{TM}}$ Lyophilised starter cultures were procured from DSM Food Specialities, P.O. Box 1, 2600 MA Delft, The Netherlands. Other solvents and reagents used were of analytical grade and from laboratories stock.

\section{Determination of fat in milk (Gerber method)}

Mixture of $90 \mathrm{ml}$ of sulphuric acid with $10 \mathrm{ml}$ of distilled water is called Gerber acid. Gerber acid ten milliiters was transferred into milk butyrometer (range 0 to $10 \%$ ) using an automatic measure. The milk sample $(10.75 \mathrm{ml})$ was slowly transferred from the side of the butyrometer closed with a lock stopper and shaken well. The mixer contents were centrifuged for $5 \mathrm{~min}$ at 1100 to $1200 \mathrm{rpm}$ and the fat that appeared as a colourless column was read directly on the butyrometer stem. 


\section{Estimation of Solids-Not-Fat (SNF)}

The SNF is the collective term given to the various components of milk other than fat. The SNF content of milk was calculated by determining the specific gravity of milk. The sample was mixed well avoiding incorporation of air or foam formation. The temperature of milk sample was adjusted to measuring temperature prescribed for the BIS lactometer $\left(27^{\circ} \mathrm{C}\right)$. Sufficient milk was poured into the glass or steel cylinder to allow free floating of lactometer. It was then placed in the milk and allowed to float till it stopped and assumed a constant level. The lactometer reading and temperature of milk was recorded at the same time. This was the lactometer reading (LR). The corrected lactometer reading (CLR) was obtained from the standard table for corresponding temperature. The SNF and/or TS content were calculated using the following formulas:

Percent SNF $=$ CLT/4 $+(0.25 *$ fat $\%)+0.44$

Percent Total Solids $=\mathrm{CLT} / 4+\left(0.25^{\star}\right.$ fat $\left.\%\right)+0.44$

\section{Preparation of yoghurt}

Fresh raw cow whole milk was taken and standardized to $3.0 \%$ fat and $8.5 \mathrm{SNF}$. It was heated to $40^{\circ} \mathrm{C}$ and added with starch at different levels $(0.5,1.0,1.5,2.0$ and $2.5 \%)$ and power sugar $(13 \%)$. It was blended and kept for $30 \mathrm{~min}$. After that, it was heated up to $65^{\circ} \mathrm{C}$ and homogenized (2000 psi). Another similar batch was prepared without homogenization. Again, the sample was heated up to $95^{\circ} \mathrm{C}$, cooled down to $40^{\circ} \mathrm{C}$ and starter culture was added. The sample was kept into incubator at $40^{\circ} \mathrm{C}$ for $7 \mathrm{hrs}$. After that, it was taken out and kept in refrigerator for further analysis.

\section{Determination of $\mathrm{pH}$ of different starch-based cow milk yoghurt}

The $\mathrm{pH}$ of the sample was measured by using $\mathrm{EUTECH}$ Instruments, $\mathrm{pH} 700, \mathrm{pH} / \mathrm{mV} /{ }^{\circ} \mathrm{C} /{ }^{\circ} \mathrm{F}$ meter at ambient temperature.

\section{Colour values measurement}

The colour of different starch-based sweetened yoghurt was measured using colourflex instrument (Hunterlab, Hunter Associates Laboratory, Teston, Virginia, USA) provided with the universal software (Ver.\$ 1.72). Before the test, the instrument was calibrated with standard black glass and white tile as specified by the manufacturer. The light source was dual beam xenon flash lamp. Colour values were expressed in terms of CIELAB software and expressed in terms $L^{*}, a^{*}, b^{*}$ uniform colour specs, where $L^{*}$ indicates lightness, ranges zero (black) to 100 (white), $a^{*}$ indicates redness $(0$ to +60$)$ and greenness $(0$ to -60$)$ and $b^{*}$ is the amount of yellowness $(0$ to +60$)$ and blueness $(0$ to -60$)$. Hue angle and chroma were determined. The different starch-based sweetened yoghurt samples were put densely up to $1 \mathrm{~cm}$ height in glass sample containers and placed on sample port facing upward. Command was given to the instrument to analyze the colour intensity of the sample by taking flash photograph of the product and results were displaced. Measurements were done in triplicates.

\section{Texture profile analysis}

Texture profile analysis plays an important role in understanding various textural attributes. The texture of yoghurt closely related to body and appearance and, hence affects the consumer acceptability. The texture profiles of different starch-based sweetened yoghurt were determined by using Texture Analyzer, TA-XT2i (M/s Stable Micro Systems, UK) fitted with $25 \mathrm{~kg}$ load cell. TA-XT2i was calibrated with $5 \mathrm{~kg}$ standard dead weight prior to use. The probe P-25 was used for texture profile analysis of different starch-based sweetened yoghurts.

\section{Viscosity analysis using modular compact rheometer}

The viscosity of the different starch-based sweetened yoghurt was measured by using modular compact rheometer instrument (Anton Paar, MCR52, Ostfildern, Germany) controlled by the computer aided software (Rheoplus/32, service ver.3.61). Cone and plate geometry (CP75-1, $1.002^{\circ}$ inclination) attachment was used with a gap of $0.149 \mathrm{~mm}$. For steady flow measurements, the rheometer was programmed for the set temperature $\left(20^{\circ} \mathrm{C}\right)$ and equilibrated for 2 min following a programmed shear rate 
changing from 0.1 to $100 \mathrm{~s}^{-1}$ in $5 \mathrm{~min}$. The temperature controlled by Peltier control system. For each test, the volume of sample placed on the plate was covered completely and excess sample was trimmed off. Each time new sample was used and all rheological measurements were carried out in triplicates. Rheological parameters: constant shear rate $(\gamma=100)$ and viscosity $(\mu)$ were recorded in software.

\section{Sensory analysis}

Sensory evaluation was done by a panel of seven trained judges to evaluate the samples for various sensory attributes. The 9-point hedonic scale was used to express the liking or disliking of products, and the panel members requested to judge the sensory quality based on colour and appearance, flavour, acidity, body and texture, and overall acceptability.

\section{Statistical analysis}

The data obtained during this study were analyzed using statistical package for social sciences (SPSS version 20).

\section{Results and Discussion}

\section{Textural, rheological and colour properties of cow milk yoghurt}

(i) Modified starch-based sweetened yoghurt

The textural and rheological properties of modified starch-based sweetened cow milk yoghurt (with and without homogenization) at different substitution levels are tabulated in Table 1 and Table 2. Stickiness increased with increased modified starch addition level for both with (from -2.231 to -5.304) and without homogenization (from -1.505 to -4.834) samples. Firmness also increased linearly for the sample of without homogenization at different incorporation level (from 3.019 to 4.887), but the homogenization samples did not show any clear difference because the modified starch lost its gelatinization power due to homogenization. Viscosity also increased with increased starch addition level and without homogenization sample showed clear and significant difference from sample to sample. The $\mathrm{pH}$ values for all cases ranged from 4.12 to 4.65 . For all samples, $L^{*}, a^{*}$ and $b^{*}$ values indicated that the samples were white, greenness and yellowness, respectively.

(ii) Potato starch-based sweetened yoghurt

Table 1. Textural, rheological and colour properties of modified starch-based sweetened cow milk yoghurt with homogenization

\begin{tabular}{lcccccc}
\hline Parameters & Control & \multicolumn{5}{c}{$\begin{array}{l}\text { Sweetened cow milk yoghurt incorporation of modified starch at different level } \\
\text { with homogenization }\end{array}$} \\
\cline { 3 - 7 } & \multicolumn{2}{c}{$0.5 \%$} & $1.0 \%$ & $1.5 \%$ & $2.0 \%$ & $2.5 \%$ \\
\hline $\mathrm{pH}$ & $4.25 \pm 0.03$ & $4.2 \pm 0.01$ & $4.13 \pm 0.013$ & $4.42 \pm 0.2$ & $4.22 \pm 0.01$ & $4.12 \pm 0.01$ \\
Textural & & & & & \\
Firmness (N) & $3.272 \pm 0.258$ & $3.941 \pm 0.203$ & $3.897 \pm 0.104$ & $3.477 \pm 0.114$ & $3.231 \pm 0.053$ & $4.409 \pm 0.113$ \\
Stickiness (N) & $-2.231 \pm 0.059$ & $-2.703 \pm 0.144$ & $-2.92 \pm 0.038$ & $-3.113 \pm 0.176$ & $-3.838 \pm 0.09$ & $-5.304 \pm 0.302$ \\
Rheological & & & & & & \\
Viscosity (Pa.s) & $0.206 \pm 0.001$ & $0.265 \pm 0.015$ & $0.275 \pm 0.017$ & $0.315 \pm 0.001$ & $0.395 \pm 0.002$ & $0.644 \pm 0.001$ \\
Colour & & & & & & \\
$\mathrm{L}^{*}$ & $82.61 \pm 0.002$ & $83.49 \pm 0.07$ & $83.97 \pm 0.1$ & $83.47 \pm 0.1$ & $82.72 \pm 0.1$ & $83.26 \pm 0.008$ \\
$\mathrm{a}^{*}$ & $-1.68 \pm 0.001$ & $-1.1 \pm 0.01$ & $-1.33 \pm 0.04$ & $-1.42 \pm 0.02$ & $-1.39 \pm 0.03$ & $-1.43 \pm 0.004$ \\
$\mathrm{~b}^{*}$ & $8.47 \pm 0.05$ & $9.58 \pm 0.06$ & $9.81 \pm 0.07$ & $9.61 \pm 0.3$ & $9.68 \pm 0.06$ & $10.07 \pm 0.03$ \\
$\mathrm{C}$ & 8.76 & 9.64 & 9.90 & 13.65 & 13.45 & 10.17 \\
$\mathrm{H}^{\circ}$ & -79.14 & -83.45 & -82.25 & -81.59 & -81.83 & -81.02 \\
\hline
\end{tabular}

Here; $C=\left(a^{2}+b^{2}\right)^{1 / 2} ; H^{\circ}=\tan ^{-1}(b / a)$ 
Table 2. Textural, rheological and colour properties of modified starch-based sweetened cow milk yoghurt without homogenization

\begin{tabular}{|c|c|c|c|c|c|c|}
\hline \multirow[t]{2}{*}{ Parameters } & \multirow[t]{2}{*}{ Control } & \multicolumn{5}{|c|}{$\begin{array}{l}\text { Sweetened cow milk yoghurt incorporation of modified starch at different level } \\
\text { without homogenization }\end{array}$} \\
\hline & & $0.5 \%$ & $1.0 \%$ & $1.5 \%$ & $2.0 \%$ & $2.5 \%$ \\
\hline $\begin{array}{l}\mathrm{pH} \\
\text { Textural }\end{array}$ & $4.36 \pm 0.02$ & $4.71 \pm 0.02$ & $4.6 \pm 0.01$ & $4.57 \pm 0.3$ & $4.48 \pm 0.03$ & $4.44 \pm 0.04$ \\
\hline Firmness (N) & $4.235 \pm 0.235$ & $3.556 \pm 0.125$ & $4.043 \pm 0.089$ & $4.435 \pm 0.182$ & $5.407 \pm 0.194$ & $6.009 \pm 0.126$ \\
\hline $\begin{array}{l}\text { Stickiness }(\mathrm{N}) \\
\text { Rheological }\end{array}$ & $-3.259 \pm 0.098$ & $-4.069 \pm 0.274$ & $-4.356 \pm 0.12$ & $-5.101 \pm 0.362$ & $-5.511 \pm 0.255$ & $-6.145 \pm 0.153$ \\
\hline $\begin{array}{l}\text { Viscosity (Pa.s) } \\
\text { Colour }\end{array}$ & $0.277 \pm 0.009$ & $0.508 \pm 0.004$ & $0.557 \pm 0.006$ & $0.702 \pm 0.002$ & $0.637 \pm 0.007$ & $0.703 \pm 0.008$ \\
\hline $\mathrm{L}^{*}$ & $83.6 \pm 0.11$ & $81.73 \pm 0.08$ & $81.43 \pm 0.07$ & $80.72 \pm 0.00$ & $83.49 \pm 0.25$ & $82.37 \pm 0.07$ \\
\hline$a^{*}$ & $-0.90 \pm 0.02$ & $-0.81 \pm 0.03$ & $-0.34 \pm 0.06$ & $-1.07 \pm 0.03$ & $-1.05 \pm 0.02$ & $-1.21 \pm 0.04$ \\
\hline$b^{*}$ & $12.98 \pm 0.04$ & $11.99 \pm 0.09$ & $12.03 \pm 0.14$ & $11.77 \pm 0.03$ & $13.11 \pm 0.2$ & $13.15 \pm 0.04$ \\
\hline $\mathrm{C}$ & 11.68 & 9.71 & 4.09 & 12.59 & 13.76 & 15.91 \\
\hline $\mathrm{H}^{\circ}$ & -86.03 & -86.14 & -88.38 & -84.81 & -85.42 & -84.74 \\
\hline
\end{tabular}

Here; $C=\left(a^{2}+b^{2}\right)^{1 / 2} ; H^{\circ}=\tan ^{-1}(b / a)$

Textural, rheological and colour properties of potato starch-based sweetened cow milk yoghurt with and without homogenization are given in Table 3 and Table 4. Firmness, stickiness and viscosity of potatobased sweetened cow milk yoghurt with homogenization samples did not show any clear significant difference. During homogenization, potato starch lost its gelatinization capacity. For the sample without homogenization, it showed linear increase of viscosity and firmness that ranged from 0.213 to 0.525 and 2.669 to 4.014 , respectively. Stickiness of without homogenization sample also increased with increased starch incorporation level. The $\mathrm{pH}$ values were within the range of 4.13 to 4.51 for all samples. All samples were white in colour with slight greenness and yellowness.

(iii) Corn starch-based sweetened yoghurt

Table 3. Textural, rheological and colour properties of potato starch-based sweetened cow milk yoghurt with homogenization

\begin{tabular}{lcccccc}
\hline Parameters & Control & \multicolumn{3}{c}{$\begin{array}{l}\text { Sweetened cow milk yoghurt incorporation of potato starch at different level with } \\
\text { homogenization }\end{array}$} \\
\cline { 2 - 7 } & & $0.5 \%$ & $1.0 \%$ & $1.5 \%$ & $2.0 \%$ & $2.5 \%$ \\
\hline $\mathrm{pH}$ & $4.42 \pm 0.01$ & $4.46 \pm 0.02$ & $4.4 \pm 0.0$ & $4.35 \pm 0.01$ & $4.33 \pm 0.01$ & $4.43 \pm 0.02$ \\
Textural & & & & & & \\
Firmness (N) & $3.649 \pm 0.114$ & $3.945 \pm 0.04$ & $3.642 \pm 0.075$ & $3.523 \pm 0.127$ & $3.351 \pm 0.114$ & $3.659 \pm 0.08$ \\
Stickiness (N) & $-2.288 \pm 0.045$ & $-3.185 \pm 0.059$ & $-4.027 \pm 0.057$ & $-3.729 \pm 0.174$ & $-3.514 \pm 0.255$ & $-3.567 \pm 0.013$ \\
Rheological & & & & & & \\
Viscosity (Pa.s) & $0.202 \pm 0.008$ & $0.322 \pm 0.007$ & $0.364 \pm 0.003$ & $0.407 \pm 0.002$ & $0.386 \pm 0.002$ & $0.355 \pm 0.005$ \\
\hline
\end{tabular}

Table 4. Textural, rheological and colour properties of potato starch-based sweetened cow milk yoghurt without homogenization

\begin{tabular}{|c|c|c|c|c|c|c|}
\hline \multirow[t]{2}{*}{ Parameters } & \multirow[t]{2}{*}{ Control } & \multicolumn{5}{|c|}{$\begin{array}{l}\text { Sweetened cow milk yoghurt incorporation of potato starch at different level } \\
\text { without homogenization }\end{array}$} \\
\hline & & $0.5 \%$ & $1.0 \%$ & $1.5 \%$ & $2.0 \%$ & $2.5 \%$ \\
\hline $\begin{array}{l}\mathrm{pH} \\
\text { Textural }\end{array}$ & $4.13 \pm 0.01$ & $4.19 \pm 0.03$ & $4.45 \pm 0.02$ & $4.51 \pm 0.02$ & $4.15 \pm 0.03$ & $4.37 \pm 0.01$ \\
\hline Firmness (N) & $2.669 \pm 0.078$ & $2.546 \pm 0.105$ & $2.975 \pm 0.089$ & $3.612 \pm 0.028$ & $3.751 \pm 0.661$ & $4.014 \pm 0.154$ \\
\hline $\begin{array}{l}\text { Stickiness }(\mathrm{N}) \\
\text { Rheological }\end{array}$ & $-2.275 \pm 0.021$ & $-3.10 \pm 0.481$ & $-3.32 \pm 0.451$ & $-3.096 \pm 0.062$ & $-3.86 \pm 0.48$ & $-3.95 \pm 0.2$ \\
\hline $\begin{array}{l}\text { Viscosity } \\
\text { (Pa.s) }\end{array}$ & $0.213 \pm 0.013$ & $0.34 \pm 0.005$ & $0.351 \pm 0.007$ & $0.385 \pm 0.008$ & $0.402 \pm 0.001$ & $0.525 \pm 0.012$ \\
\hline
\end{tabular}


The textural, rheological and colour properties data of corn starch-based sweetened cow milk yoghurt with and without homogenization are presented in Table 5 and Table 6 . Firmness and stickiness did not show any clear significant difference for the homogenization sample. Due to homogenization, starch lost and reduced its pasting properties. Viscosity increased with the increase of corn starch incorporation for homogenization sample. The $\mathrm{pH}$ values were ranged from 4.44 to 5.17. The colour values of all samples were same as before. For unhomogenized sample, viscosity, firmness and stickiness increased with increased of corn starch incorporation level.

Table 5. Textural, rheological and colour properties of corn starch-based sweetened cow milk yoghurt with homogenization

\begin{tabular}{lcccccc}
\hline Parameters & Control & \multicolumn{3}{c}{$\begin{array}{l}\text { Sweetened cow milk yoghurt incorporation of corn starch at different level with } \\
\text { homogenization }\end{array}$} \\
\cline { 3 - 7 } & & $0.5 \%$ & $1.0 \%$ & $1.5 \%$ & $2.0 \%$ & $2.5 \%$ \\
\hline $\mathrm{pH}$ & $5.15 \pm 0.01$ & $4.44 \pm 0.02$ & $4.68 \pm 0.02$ & $4.58 \pm 0.01$ & $4.9 \pm 0.01$ & $5.17 \pm 0.02$ \\
Textural & & & & & & \\
Firmness (N) & $3.019 \pm 0.038$ & $4.194 \pm 0.172$ & $3.673 \pm 0.051$ & $3.449 \pm 0.038$ & $3.957 \pm 0.084$ & $4.296 \pm 0.171$ \\
Stickiness (N) & $-1.505 \pm 0.03$ & $-2.817 \pm 0.096$ & $-3.592 \pm 0.132$ & $-3.439 \pm 0.138$ & $-3.478 \pm 0.062$ & $-3.17 \pm 0.312$ \\
Rheological & & & & & & \\
Viscosity (Pa.s) & $0.142 \pm 0.002$ & $0.252 \pm 0.002$ & $0.322 \pm 0.001$ & $0.33 \pm 0.002$ & $0.445 \pm 0.003$ & $0.515 \pm 0.005$ \\
\hline
\end{tabular}

Table 6. Textural, rheological and colour properties of corn starch-based sweetened cow milk yoghurt without homogenization

\begin{tabular}{lcccccc}
\hline Parameters & Control & \multicolumn{5}{c}{$\begin{array}{l}\text { Sweetened cow milk yoghurt incorporation of corn starch at different level without } \\
\text { homogenization }\end{array}$} \\
\cline { 3 - 7 } & & $0.5 \%$ & $1.0 \%$ & $1.5 \%$ & $2.0 \%$ & $2.5 \%$ \\
\hline pH & $4.45 \pm 0.01$ & $4.5 \pm 0.02$ & $4.53 \pm 0.03$ & $4.65 \pm 0.01$ & $4.51 \pm 0.02$ & $4.49 \pm 0.01$ \\
Textural & & & & & \\
Firmness (N) & $3.019 \pm 0.038$ & $3.674 \pm 0.11$ & $3.96 \pm 0.093$ & $4.568 \pm 0.203$ & $4.595 \pm 0.051$ & $4.887 \pm 0.236$ \\
Stickiness (N) & $-1.505 \pm 0.03$ & $-3.578 \pm 0.144$ & $-4.009 \pm 0.018$ & $-4.849 \pm 0.034$ & $-4.585 \pm 0.352$ & $-4.834 \pm 0.465$ \\
Rheological & & & & & & \\
Viscosity (Pa.s) & $0.142 \pm 0.002$ & $0.464 \pm 0.006$ & $0.558 \pm 0.006$ & $0.636 \pm 0.005$ & $0.689 \pm 0.009$ & $0.761 \pm 0.007$ \\
\hline
\end{tabular}

\section{Sensory properties of different starch-based sweetened cow milk yoghurt}

Yoghurt from unhomogenized milk for all treatments responded positively with the level of incorporation of different starches but the homogenized samples responded positively in a few cases only. Colour values, however, remained unchanged in all treatments. So, the results of sensory evaluation of different starchbased yoghurt from cow milk without homogenization are reported only.

The sensory attributes of sweetened cow milk yoghurt with incorporation of modified starch at different levels without homogenization based on colour and appearance, flavour, acidity, body and texture, and overall acceptability were significantly $(p<0.01)$ different $($ Table 7$)$. Thus, the sensory attributes of all the samples showed various degrees of acceptability. However, the overall acceptability was the highest at $1.0 \%$ incorporation level of modified starch without homogenization.

Similarly, the sensory properties of sweetened cow milk yoghurt incorporation of potato starch at different level without homogenization are given in Table 8. The sensory attributes of different samples showed various degrees of acceptability and were significantly different $(p<0.01)$. The overall acceptability was the highest at $1.5 \%$ incorporation level of potato starch without homogenization.

The sensory qualities based on different attributes for sweetened cow milk yoghurt incorporation of corn starch at different levels without homogenization are given in Table 9. It is seen that all these sensory scores of different samples were significantly different $(p<0.01)$ and thus, the samples showed various degrees of acceptability. The highest overall acceptability was found at $2.0 \%$ for incorporation level of corn starch for without homogenization. 
Table 7. Sensory properties of modified starch-based sweetened cow milk yoghurt without homogenization

\begin{tabular}{|c|c|c|c|c|c|c|c|}
\hline \multirow[t]{2}{*}{ Sensory attributes } & \multirow[t]{2}{*}{ Control } & \multicolumn{5}{|c|}{$\begin{array}{l}\text { Sweetened cow milk yoghurt incorporation of modified starch at } \\
\text { different level without homogenization }\end{array}$} & \multirow[t]{2}{*}{ LSD } \\
\hline & & $0.5 \%$ & $1.0 \%$ & $1.5 \%$ & $2.0 \%$ & $2.5 \%$ & \\
\hline Colour \& appearance & $7.5^{\mathrm{a}}$ & $7.7^{a}$ & $7.7^{\mathrm{a}}$ & $7.6^{\mathrm{a}}$ & $7.7^{a}$ & $7.8^{\mathrm{a}}$ & $\mathrm{NS}^{* *}$ \\
\hline Flavour & $7.4^{\mathrm{abc}}$ & $7.2^{\mathrm{C}}$ & $7.5^{\mathrm{abc}}$ & $7.3^{\mathrm{bc}}$ & $7.6^{\mathrm{ab}}$ & $7.7^{\mathrm{a}}$ & $0.3203^{*}$ \\
\hline Acidity & $7.4^{\mathrm{ab}}$ & $7.1^{\mathrm{c}}$ & $7.1^{\mathrm{c}}$ & $7.3^{\mathrm{bc}}$ & $7.5^{\mathrm{ab}}$ & $7.6^{\mathrm{a}}$ & 0.2448 \\
\hline Body \& Texture & $7.3^{a b}$ & $7.5^{\mathrm{a}}$ & $7.7^{\mathrm{a}}$ & $7.0^{\mathrm{b}}$ & $7.5^{\mathrm{a}}$ & $7.0^{\mathrm{b}}$ & 0.3739 \\
\hline Overall acceptability & $7.4^{a}$ & $7.4^{a}$ & $7.4^{a}$ & $7.3^{a}$ & $7.7^{\mathrm{a}}$ & $7.5^{\mathrm{a}}$ & NS \\
\hline
\end{tabular}

${ }^{*}=$ Significant at $1 \%$ level of probability; ${ }^{* *} \mathrm{NS}=$ Not significant

Table 8. Sensory properties of potato starch-based sweetened cow milk yoghurt without homogenization

\begin{tabular}{lccccccc}
\hline Sensory attributes & Control & \multicolumn{2}{l}{$\begin{array}{l}\text { Sweetened cow milk yoghurt incorporation of potato starch at } \\
\text { different level without homogenization }\end{array}$} & LSD \\
\cline { 2 - 7 } & & $0.5 \%$ & $1.0 \%$ & $1.5 \%$ & $2.0 \%$ & $2.5 \%$ & \\
\hline Colour \& appearance & $7.1^{\mathrm{c}}$ & $7.8^{\mathrm{a}}$ & $7.8^{\mathrm{a}}$ & $7.8^{\mathrm{a}}$ & $7.4^{\mathrm{b}}$ & $7.6^{\mathrm{ab}}$ & $0.2609^{*}$ \\
Flavour & $6.8^{\mathrm{c}}$ & $7.4^{\mathrm{b}}$ & $7.8^{\mathrm{ab}}$ & $7.9^{\mathrm{a}}$ & $6.9^{\mathrm{c}}$ & $7.4^{\mathrm{b}}$ & 0.4120 \\
Acidity & $7.2^{\mathrm{bc}}$ & $7.3^{\mathrm{bc}}$ & $7.5^{\mathrm{b}}$ & $7.8^{\mathrm{a}}$ & $7.1^{\mathrm{c}}$ & $7.5^{\mathrm{b}}$ & 0.2998 \\
Body \& Texture & $7.0^{\mathrm{c}}$ & $7.4^{\mathrm{b}}$ & $7.4^{\mathrm{b}}$ & $7.8^{\mathrm{a}}$ & $7.1^{\mathrm{c}}$ & $7.4^{\mathrm{b}}$ & 0.2065 \\
Overall acceptability & $7.0^{\mathrm{c}}$ & $7.5^{\mathrm{ab}}$ & $7.7^{\mathrm{a}}$ & $7.7^{\mathrm{a}}$ & $6.8^{\mathrm{c}}$ & $7.2^{\mathrm{abc}}$ & 0.5068 \\
\hline
\end{tabular}

* $=$ Significant at $1 \%$ level of probability

Table 9. Sensory properties of corn starch-based sweetened cow milk yoghurt without homogenization

\begin{tabular}{lcccccccc}
\hline Sensory attributes & Control & \multicolumn{2}{c}{$\begin{array}{l}\text { Sweetened cow milk yoghurt incorporation of corn starch at } \\
\text { different level without homogenization }\end{array}$} & LSD \\
\cline { 2 - 7 } & & $0.5 \%$ & $1.0 \%$ & $1.5 \%$ & $2.0 \%$ & $2.5 \%$ & \\
\hline Colour \& appearance & $7.0^{\mathrm{c}}$ & $7.8^{\mathrm{a}}$ & $7.8^{\mathrm{a}}$ & $7.8^{\mathrm{a}}$ & $7.4^{\mathrm{b}}$ & $7.1^{\mathrm{c}}$ & $0.2609^{*}$ \\
Flavour & $6.3^{\mathrm{c}}$ & $6.7^{\mathrm{a}}$ & $7.4^{\mathrm{bc}}$ & $7.8^{\mathrm{a}}$ & $7.7^{\mathrm{ab}}$ & $7.3^{\mathrm{c}}$ & 0.3539 \\
Acidity & $6.8^{\mathrm{c}}$ & $6.9^{\mathrm{bc}}$ & $7.3^{\mathrm{ab}}$ & $7.4^{\mathrm{a}}$ & $7.3^{\mathrm{ab}}$ & $7.5^{\mathrm{a}}$ & 0.4539 \\
Body \& Texture & $6.8^{\mathrm{c}}$ & $7.2^{\mathrm{bc}}$ & $7.5^{\mathrm{ab}}$ & $7.2^{\mathrm{bc}}$ & $7.8^{\mathrm{a}}$ & $7.6^{\mathrm{ab}}$ & 0.4628 \\
Overall acceptability & $6.6^{\mathrm{c}}$ & $7.2^{\mathrm{b}}$ & $7.7^{\mathrm{a}}$ & $7.6^{\mathrm{a}}$ & $7.7^{\mathrm{a}}$ & $7.3^{\mathrm{ab}}$ & 0.3702 \\
\hline
\end{tabular}

* $=$ Significant at $1 \%$ level of probability

\section{Conclusion}

The purpose of this study was to incorporate different starches to sweetened cow milk yoghurt for increasing textural and rheological properties. The firmness, stickiness and viscosity increased linearly with increase of incorporation level of different starches without homogenization. During homogenization, all starches lost their gelatinization capacity because of that all samples did not show any significant difference for textural and rheological properties. The incorporation level $(2 \%)$ was higher for corn starch than for potato and modified starch. Further studies are needed for using starches to incorporate into the cow milk sweetened yoghurt.

\section{Acknowledgement}

The authors gratefully thank to the Food Security Center (FSC), University of Hohenheim as scholarship provider, and German Academic Exchange Service (DAAD) and the German Federal Ministry for Economic Cooperation and Development (BMZ) authorities for the financial support to carry out this work at the Division of Dairy Technology (Food Technology Lab.), National Dairy Research Institute (NDRI), Karnal, Haryana, India. 


\section{References}

Bouzar, F., Cerning, J. and Desmazeaud, M. 1997. Exopolysaccharide production and texture-promoting abilities of mixed-strain starter cultures in yogurt prodiction. J. Dairy Sci. 80: $2310-2317$.

Brown, W. H. and Poon, T. 2005. Introduction to Organic Chemistry. $3^{\text {rd }}$ Ed., John Wiley \& Sons Inc., USA.

Hassan, A.N., Corredig, M. and Frank, J.F. 2001. Voscoelastic properties of yourt made with ropy and nonropy exopolysaccharides producing cultures. Milchwissenschaft, 56(12): 684 - 687.

Hilliam, M. 2003. Future for dairy products and ingredients in the functional foods market. Australian J. Dairy Tech., $58: 98$ - 103.

Hsu, S., Lu, S. and Huang, C. 2000. Viscoelastic changes of rice starch suspensions during gelatinization. J. Food Sci., $65: 215-$ 220.

Jenkins, P. 1994. X-ray and neutron scattering studies on starch granule structure. PhD Thesis. University of Cambridge.

Jones, A.N. 2002. Density of milk. The Physics Factbook.

Kalab, M., Allan-Wojtas, P. and Phipps-Todd, B.E. 1983. Development of microstructure in set-style nonfat yoghurt. A review. Food Microstr. 2: $51-66$.

Kwak, H.S., Ahn, J.J., Lee, K.W. and Suh, D.S. 1996. Flavour and sensory attributes in yoghurt. Food and Biotechnology, 5: $94-$ 98.

Lii, C.Y., Tsai, M.L. and Tseng, K.H. 1996. Effect of amylose content on rheological property of rice starch. Cereal Chemistry, 73: $415-420$

Lucey, J.A. and Singh, H. 1998. Formation and physical properties of acid milk gels. A review. Food Res. Int. $30: 529-542$.

Nurul, I.M., Azemi, B.M.N.M. and Manan, D.M.A. 1999. Rheological behaviour of sago (Metroxylon sagu) starch paste. Food Chemistry, 64: 501- 505.

Stanley, G. 1998. Microbiology of fermented milk products. In the Technology of Dairy Products. Early ed., Thomson Science Ltd. Hong Kong. pp. 50-79.

Svegmark, K. and Hermansson, A.K. 1993. Microstructure and rheological properties of composites of potato starch garnules and amylose: a comparison of observed and predicted structure. Food structure, 12: $181-193$.

Tamime, A.Y. and Robinson, R.K. 1999. Yoghurt Science and Technology. Woodhead Publishing Ltd., Cambridge, UK. pp. 432 475.

Zobel, H.F., Young, S.N. and Roca, L.A. 1998. Starch gelatinization. An X-ray diffraction study. Cereal Chemistry, 66: 443 - 446. 